\title{
VIGIAR E PUNIR NA ESCOLA: a microfísica do poder
}

PANIAGO, Maria de Lourdes Faria dos Santos Doutoranda em Lingüística/UNESP Docente CCL/CAJ/UFG

lurdinhapaniago@terra.com.br

RESUMO: O objetivo do presente trabalho é investigar a teoria de Michel Foucault (1926-1984), principalmente as descritas nas obras "Vigiar e Punir" e "Microfísica do Poder", no que se referem a práticas de subjetivação no contexto escolar, ou seja, a forma como a escola tem fabricado sujeitos constitui o principal foco dessa investigação.

Palavras-chave: Práticas de Subjetivação - Escola - Michel Foucault - Panoptismo.

ABSTRACT: The aim of this paper is to investigate Michel Foucault's (1926-1984) theory, mainly the ones described in his works Discipline and Punish and Micro-physics of Power, concerning the practices of subjectivization in the school context, that means, the way the school has fabricated subjects is the main focus of this investigation.

Key-words: practices of subjectivization, school, Michel Foucault, panopticism.

Introdução

Para Michel Foucault (2001a), o sujeito é sempre o resultado de uma prática, ou seja, o sujeito é sempre fabricado. Nesse sentido, a educação escolarizada funciona como dispositivo encarregado de fabricar um tipo bem determinado de indivíduos.

Muitos leitores de Foucault acreditam que seu principal foco de interesse era o poder. No entanto, o próprio filósofo francês se encarregou de esclarecer, em um de seus últimos trabalhos, que seu objetivo fora sempre o sujeito (Foucault, 1995). Depois de esclarecer que existem três tipos de lutas: lutas contra formas de dominação (étnica, social e religiosa), lutas contra formas de exploração que separam os indivíduos daquilo que eles produzem, e lutas contra as formas de subjetivação, Foucault esclarece que são as lutas contra a sujeição que têm se tornado cada vez mais importantes, porque o Estado moderno ocidental se apropriou de uma antiga tecnologia de poder, o poder pastoral. Ou seja, para Foucault, longe de considerarmos que o Estado moderno se desenvolveu ignorando os indivíduos, devemos vê-lo como uma sofisticada estrutura, que pretende, contando com modelos específicos, dar novas formas a esta individualidade.

Determinadas características do poder pastoral sofreram alterações para melhor atender aos interesses do Estado. Assim, se antes da incorporação pelo Estado, o poder pastoral tinha como objetivo assegurar a salvação individual no mundo divino, depois essa estratégia de poder passou a se preocupar com a salvação no mundo terreno. Se antes esse poder era exercido somente pela igreja, depois ele passou a ser exercido por uma série de outros agentes. 
Assim, novos agentes além do próprio Estado - polícia, empreendimentos privados, sociedades de bem-feitores e de filantropos, família, hospitais, escolas - passaram a se preocupar em assegurar saúde, bem-estar e segurança aos indivíduos. O poder pastoral, então, passou a ser exercido por todo corpo social para assegurar o bom funcionamento do Estado. O foco de interesse não era somente o indivíduo, mas a população.

Esse poder é então exercido por instituições que Foucault chama de "blocos disciplinares" ou "disciplinas". Na escola, há toda uma série de procedimentos de poder que asseguram a fabricação de indivíduos de determinado tipo.

\section{O conceito de poder em Foucault}

O poder, para Foucault, não é algo que se possa possuir, porque não é um bem alienável do qual se possa ter a propriedade. Por isso, qualquer que seja a sociedade, não existe divisão entre os que têm e os que não têm poder. O poder se exerce ou se pratica. Resumindo, Foucault afirma que "o poder não existe" (Foucault, 2001b, p. 248), o que existem são práticas, relações de poder. Machado (2001, p. XIV), na introdução que fez para o Microfísica do Poder (Foucault, 2001b), sintetiza muito bem as idéias do filósofo sobre o poder: "ele é luta, afrontamento, relação de força, situação estratégica. Não é um lugar, que se ocupa, nem um objeto, que se possui. Ele se exerce, se disputa". (Machado, 2001, p. XV).

O poder, então, circula. No contexto escolar, por exemplo, não são apenas os professores e diretores que exercem o poder. Os estudantes, os pais, os diretores, os funcionários da secretaria também o exercem. A partir dessa constatação, Foucault chega ao que ele chama de micropráticas do poder. Esse aspecto da teoria foucaultiana não foi recebido sem contestação, já que se constitui em uma proposta de abandono das teses althusserianas tão largamente aceitas - que afirmam que todo poder emana do Estado para seus Aparelhos Ideológicos. Para Foucault, a possibilidade de existência do poder "não deve ser procurada na existência primeira de um ponto central, num foco único de soberania de onde partiriam formas derivadas e descendentes" (Foucault, 2001a, p. 89). O objetivo de Foucault não era minimizar a função do Estado, mas apenas divergir da idéia bastante aceita na época de que todo o poder emanava dele.

Eu não quero dizer que o Estado não seja importante; o que eu quero dizer é que as relações de poder, e, conseqüentemente sua análise se estendem além dos limites do Estado. Em dois sentidos: em primeiro lugar porque o Estado, com toda a onipotência do seu aparato, está longe de ser capaz de ocupar 
todo o campo de reais relações de poder, e principalmente porque o Estado apenas pode operar com base em outras relações de poder já existentes. O Estado é a superestrutura em relação a toda uma série de redes de poder que investem o corpo, sexualidade, família parentesco, conhecimento, tecnologia etc. (Foucault, 1980, p. 122) ${ }^{1}$

A intenção de Foucault era detectar a existência de poder que não se originava no Estado ou em seus "aparelhos". Para ele, não haverá mudança na sociedade se não houver modificação nos mecanismos de poder externos aos aparelhos de Estado, "a um nível muito mais elementar, quotidiano" (Foucault, 2001b, p. 150). Mas, se isso a priori indica uma mudança do foco de análise do centro para a periferia, não significa que esse filósofo acredite que o poder possa estar localizado em outro lugar que não o Estado. É condição sine qua non para a compreensão das teses foucaultianas tomar o poder como não localizável em nenhum ponto específico da estrutura social. Para Foucault, o poder funciona como uma rede que incluiu a todos, ou seja, da qual ninguém pode esquivar-se, para a qual não existe nada que lhe possa ser exterior. Foucault, entretanto, preocupa-se em esclarecer que, mesmo em instituições fortemente hierarquizadas - o exército por exemplo -, em que a rede de poder possua uma forma piramidal, o "ápice" não é a "fonte" ou o "princípio" de onde todo o poder emana, porque o vértice (os comandantes) e a base (os comandados) da hierarquia se apoiam e se condicionam reciprocamente (Foucault, 2001b, p. 221).

Perceber a microfísica do poder não se traduz apenas em deslocar a análise do ponto de vista espacial, mas principalmente analisar o nível em que ela ocorre. Ou seja, não basta concluir que não há um ponto central de onde o poder irradia toda a sua fortaleza; é preciso compreender que analisar a microfísica do poder significa entender os procedimentos técnicos que têm por objetivo o controle minucioso do corpo. Não apenas o produto, mas todo o processo é alvo do micropoder, seus mais detalhados gestos.

Para Foucault, é uma concepção simplesmente jurídica que subjaz a análise do poder pela repressão, ou seja, estar-se-ia identificando o poder basicamente a uma lei que é sempre proibidora, preocupada sempre em dizer não. Ele classifica essa noção puramente negativa do poder como "estreita" e "esquelética", argumentando que, se assim fosse, se o poder não fizesse outra coisa a não ser dizer não, ele não seria obedecido. Ou seja, para esse filósofo, o que faz com que o poder seja aceito é justamente o fato de que ele não é apenas uma intolerável carga da qual não se possa escapar, mas na verdade, ele atravessa toda a

\footnotetext{
${ }^{1}$ FOUCAULT, M. L'impossible prison, recherches sur le systeme pénitentiaire au XIX siècle. Paris, Éd. du Seuil. (Apud MAIA, 1995, P. 88)
} 
sociedade, produzindo coisas, induzindo ao prazer, formando saber, produzindo discursos. Deve-se, portanto,

considerá-lo como uma rede produtiva que atravessa todo o corpo social muito mais do que uma instância negativa que tem por função reprimir (Foucault, 2001b, p. 8)

Como se vê, Foucault desenvolveu uma concepção não-jurídica do poder. Ou seja, a premissa básica de Foucault é que as relações de poder não se dão fundamentalmente nem ao nível do direito, nem ao nível da violência. Dessa forma, "nem são basicamente contratuais nem unicamente repressivas" (Machado, 2001, p. XV). O modelo jurídico, que faz da lei a manifestação essencial do poder, pressupondo o indivíduo como sujeito de direitos naturais ou poderes primitivos, deve ser abandonado para que se consiga fazer uma análise concreta das relações de poder (Foucault, 1974-82) ${ }^{2}$

O poder não é sempre negativo. A essa concepção, tão absolutamente enraizada na sociedade ocidental, principalmente a partir das teses marxistas e dos escritos althusserianos, Foucault acrescenta uma outra, muito mais polêmica. Para Foucault, o poder produz e transforma, e é essa característica que faz com que seja não apenas negativo. Foucault pretende mostrar que o poder não deve ser visto essencialmente ligado à dominação e à repressão. O poder "produz real; produz domínios de objetos e rituais de verdade" (Foucault, 2002).

E é justamente por possuir essa eficácia produtiva que o poder volta-se para o sujeito, ou mais especificamente, para o corpo do sujeito, não essencialmente para reprimi-lo, mas para adestrá-lo, torná-lo dócil e útil para a sociedade (Foucault, 2002).

Explicar o poder apenas a partir de sua função repressiva significa omitir da análise seu âmago, sua essência. Ao poder não interessa a simples repressão e dominação dos homens. Ao invés disso, importa que suas mais detalhadas atividades sejam geridas, para fazer com que se tornem sempre mais úteis.

\section{Governamentalidade}

O exercício de poder, para Foucault, é - em toda acepção da palavra - um modo de ação sobre a ação dos outros. Deriva daí um conceito muito importante, que é amplamente utilizado pelos teóricos que se ocupam em estudar as relações de poder: governamentalidade.

\footnotetext{
${ }^{2}$ Foucault, M. Anuário do Collège de France 1974-82. Apud MAIA, 1995.
} 
Para ele, governar é "estruturar o eventual campo de ação dos outros” (Foucault, 1995, p. 244), o que significa retirar da noção de poder qualquer conexão com o conceito de repressão.

Assim, não há possibilidade de governo sobre ações onde as determinações estão saturadas. Apesar do aparente paradoxo, Foucault afirma que só há relações de poder sobre sujeitos livres, ou seja, a liberdade é precondição da existência do poder. A escravidão, então, constitui uma "relação física de coação", porque não há o que governar uma vez que o sujeito não tem mais de uma possibilidade de conduta.

Pode-se deduzir daí que Foucault, sem rejeitar a importância da utilização da violência por aqueles que exercem o poder, afirma que a violência pode ser utilizada mas não é um princípio inerente às relações de poder.

Ele [o poder] não é em si mesmo uma violência que, às vezes, se esconderia, ou um consentimento que, implicitamente, se reconduziria. Ele é um conjunto de ações sobre ações possíveis; ele opera sobre o campo de possibilidade onde se inscreve o comportamento dos sujeitos ativo. (Foucault, 1995, p. 243)

Maia (1995, p. 90), ao analisar este ponto da teoria foucaultiana, afirma que as relações de poder somente podem ser articuladas com base em dois elementos: a) aquele sobre quem o poder é exercido deve ser plenamente reconhecido como uma pessoa que age; b) todo um campo de respostas, reações, resultados, e possíveis invenções seja aberto. Maia retoma aqui, de forma sistematizada, dois grandes pilares básicos da concepção foucaultiana de poder: a) só há possibilidade de governo onde houver possibilidade de ação e b) onde há poder há resistência.

\section{Resistência}

Não se pode falar sobre o conceito de poder em Foucault sem que se compreenda outro pressuposto fundamental na teoria foucaultiana: todo poder pressupõe resistência. $\mathrm{Ou}$, nas palavras do próprio filósofo, "lá onde há poder há resistência e, no entanto (ou melhor, por isso mesmo) esta nunca se encontra em posição de exterioridade em relação ao poder". (Foucault, 2001a, p. 91)

Foucault alerta que não se pode ignorar o "caráter estritamente relacional das correlações de poder”. Ou seja, em toda relação de poder há uma multiplicidade de pontos que representam "o papel de adversário, de alvo, de apoio, de saliência que permite a preensão". Não se pode, em outras palavras, cometer dois enganos: conceber o poder como uma pista de mão única e considerar que nas relações de poder existe um ponto de resistência. As 
resistências são assim a contrapartida nas relações de poder e se constituem como o “interlocutor irredutível".

As resistências ocorrem de maneira irregular. É fácil identificar os pontos de resistências nas grandes revoltas, que provocam rupturas definitivas na história. No entanto, não apenas nesse tipo de relação de poder há resistência. Como dissemos, a resistência é inerente ao poder. Por isso, os grandes pontos de resistência são mais raros; os mais comuns são os "móveis" e "transitórios", que "introduzem na sociedade clivagens que se deslocam, rompem unidades e suscitam reagrupamentos, percorrem os próprios indivíduos, recortandoos e os remodelando, traçando neles, em seus corpos e almas, regiões irredutíveis". (Foucault, 2001a, p.92)

Assim como há uma microfísica do poder, assim como o poder deve ser analisado como estando em toda parte, como uma rede que permeia toda a sociedade, também a resistência deve ser vista, na medida em que "atravessa as estratificações sociais e as unidades individuais" (p.92). Em outras palavras, podemos dizer que, assim como o poder, não há propriamente um lugar de resistência, mas sim pontos extremamente móveis e transitórios, que também se distribuem por toda a rede social.

Como se viu, então, não se pode falar de poder em Foucault sem falar de resistência.

Pesquisar relações de poder na escola é pesquisar, na mesma medida, pontos de resistência. Deve-se, no entanto, ficar atento para encontrar pontos de resistência não apenas nos momentos em que os alunos se organizam em grupo em levantes definitivos. A resistência na escola, como em qualquer parte, está em todos os lugares, em micropráticas pulverizadas. A resistência está tanto na palavra como no silêncio, tanto no gesto como na imobilidade.

\section{Vigiar e Punir}

Em Vigiar e Punir (2002), Foucault mostra como, a partir dos séculos XVII e XVIII, houve um verdadeiro "desbloqueio tecnológico da produtividade do poder" (Foucault, 2001b, p. 8). Não apenas novos aparelhos de Estado foram desenvolvidos, mas principalmente instaurou-se uma nova "'economia' do poder", ou seja, todo um conjunto de dispositivos para circular os efeitos de poder contínua e ininterruptamente; aparelhos muito distintos dos anteriores, o que torna essa nova forma de poder totalmente incompatível com as relações de soberania (Foucault, 2001b, p. 187). As novas tecnologias, além de serem muito 
menos dispendiosas do ponto de vista econômico, são muito mais eficazes, na medida em que proporcionam menores possibilidades de resistências.

\section{Corpos dóceis}

Foucault inicia a parte III do Vigiar e Punir (2002) com um capítulo que se chama Corpos dóceis, em que ele nos alerta sobre a descoberta do corpo como objeto e alvo do poder. É dócil um corpo que pode ser transformado para ser utilizado.

Para Foucault, o século XVIII trouxe algumas modificações sobre este controle do corpo. O corpo sempre esteve submetido a controles muito rígidos em qualquer sociedade, no entanto, o esquema de docilidade do século XVIII é inovador em alguns aspectos. Primeiramente, porque amplia a escala do controle, ou seja, passou-se a trabalhar muito mais detalhadamente o corpo, procurando controlá-lo não apenas no que faz, mas também na forma como o faz e no tempo que demora para fazê-lo. Em seguida, o objeto do controle também mudou: passou-se a ter como principal objetivo a eficácia dos movimentos, sua economia. Por fim, a modalidade do controle, que passou a implicar uma coerção constante, não apenas para controlar o produto, mas principalmente para se ter controle sobre o processo.

O que se quer, portanto, são corpos dóceis para se ter corpos úteis, e isso é conseguido, segundo Foucault (2002), através de métodos que ele chama de disciplinas, que se preocupam essencialmente com a organização do espaço, do tempo e das capacidades. $\mathrm{O}$ método preocupa-se inicialmente com a distribuição dos indivíduos no espaço. Além das cercas a fechar conventos, escolas, hospitais, surge então o que Foucault denomina de quadriculamento, que tem como principal objetivo evitar que os indivíduos formem grupos desordenados e perigosos. Através dessa técnica, permanece "cada indivíduo no seu lugar; e em cada lugar, um indivíduo" (p. 123). Na escola, a colocação das carteiras em fileiras começa nessa época e tinha como principal objetivo fazer com que todos ficassem sob a mira do olhar do mestre, principalmente porque sobrava espaço entre uma fila e outra para que o professor pudesse aí caminhar. Já nessa época, o critério para a distribuição dos alunos não era aleatório; a distribuição dependia da idade, do desempenho e do comportamento. Não é difícil perceber as conseqüências dessa técnica na escola: ao colocar os alunos em filas, a função de vigilância foi amplamente facilitada; ao distribuir os alunos em função de seus comportamentos e desempenhos, pode-se hierarquizar e, a partir daí, premiar ou punir, bastando para isso mudar um aluno de lugar. 
Além do espaço, a disciplina preocupa-se também com o tempo. É por isso que na escola há hora para tudo. Os rituais na escola pressupõem não apenas um horário para chegar e outro para sair, mas também um horário para rezar, para lavar as mãos, para lanchar, para escovar os dentes; a divisão do tempo se torna cada vez mais detalhada, para que se tenha maior produtividade, ou seja, é necessário um controle constante para que se tenha total utilidade na utilização do tempo, para que se anule tudo que possa perturbar e distrair.

A organização das capacidades nas escolas contribui para que o processo escolar seja dividido em níveis e estes em séries, com a preocupação sempre de conseguir maior produtividade; por isso é que o aluno só é promovido para outra série se for considerado apto para isso. As atividades serão consideradas como apropriadas dependendo do resultado do exame realizado no estágio anterior. Pode-se também considerar que a divisão do tempo possa ser relacionada à tentativa de dissipar os grupos de indivíduos; por exemplo, nas escolas superiores é comum a semestralização das séries, em que os alunos podem escolher que disciplinas vão cursar, o que traz a conseqüência clara de o aluno não ter uma turma específica ao longo do curso.

\section{Adestramento}

Para Foucault (2002), o grande objetivo do poder disciplinar é o adestramento, que se utiliza, para isso, de instrumentos simples: a vigilância hierárquica, que vigia; a sanção normalizadora, que normaliza; e o exame, que vigia e normaliza.

O antigo esquema do quadriculamento é substituído por formas mais sofisticadas. O diagrama do tipo acampamento permite que se possa hierarquizar a vigilância, de forma que uns controlem os outros. É por isso que não eram incomuns naquela época escolas, zoológicos, hospitais ou cidades inteiras que tinham o acampamento como forma estrutural, para possibilitar maior vigilância e possibilitar um maior número de olhares vigias. A preocupação com a vigilância era tanta que havia necessidade de controle em todos os momentos; por exemplo, nas escolas, os alunos eram controlados durante as refeições, a partir da colocação de estrados mais altos onde eram colocadas as mesas dos inspetores, e durante o tempo que ficavam no banheiro, através da instalação de meias-portas que permitiam que tanto os pés quanto a cabeça dos alunos fossem vista pelo vigia (Foucault, 2002)

Não apenas na escola, mas também em outros blocos disciplinares, como a oficina ou o exército, tudo o que não está de acordo com um padrão estabelecido é passível de punição. Na escola, vemos que são punidos não apenas as infrações que se relacionam 
diretamente com o processo escolar, mas tudo que está em desacordo com o tipo de sujeito que se quer fabricar, por isso encontram-se formas para punir tanto os desempenhos insuficientes dos alunos como a falta de higiene em seus corpos e roupas ou as suas atitudes grosseiras. O castigo disciplinar tem, assim, o objetivo de reduzir os desvios a partir de um padrão previamente estabelecido com o objetivo de normalizar, porque pretende, ao eliminar as distorções, que todos se pareçam uns com os outros e todos se pareçam com o padrão fixado.

O exame combina as duas técnicas: não apenas vigia mas também normaliza. Uma prova na escola tem, de fato, essas duas funções; ela serve para medir e vigiar o desempenho dos alunos a partir da nota que obtiveram e serve para normalizar na medida em que há comparação do desempenho dos diversos alunos; o aluno que tirou uma nota abaixo da média é sempre pressionado para que se saia melhor nos próximos exames e assim se pareça mais com o aluno que tirou uma nota maior. O exame acarreta então duas possibilidades que se relacionam entre si: ao mesmo tempo em que permite a constituição do indivíduo como objeto descritível, com o objetivo de analisar seus traços particulares, permite também a constituição de um sistema comparativo, que possibilita a mensuração dos desvios do grupo como um todo. Para Foucault (2002), o exame ocupa um papel fundamental também porque expõe para o próprio indivíduo examinado seu "verdadeiro eu". Como resultado dos exames, os indivíduos são classificados e objetivados. Mas, por outro lado, os indivíduos constroem suas identidades, na proporção em que esses objetivos e essas classificações são incorporados por eles.

Foucault conclui, então, que as disciplinas efetivamente fabricam indivíduos. Para ele, "o indivíduo é sem dúvida o átomo fíctício de uma representação "ideológica" da sociedade; mas é também uma realidade fabricada por essa tecnologia específica de poder que se chama disciplina”. (2002, p.161).

E é assim que, como já foi dito, Foucault defende que o poder não é necessariamente negativo. O poder pode não ser repressivo; pode tornar mais fácil e provável determinada coisa, na medida em que incita ou seduz. Assim, a positividade do poder encontra-se no fato de que existem coisas que são construídas a partir da organização que o poder impõe; cabe à disciplina, não apenas a função de eliminar os desvios, mas de efetivamente aumentar a utilidade dos indivíduos.

Por isso, Foucault alerta que temos que deixar de descrever sempre os efeitos de poder em termos negativos: ele "exclui", "reprime", "recalca", “censura", "abstrai", "mascara", "esconde", porque verdadeiramente "o poder produz realidade; produz campos de 
objetos e rituais da verdade". Não apenas o indivíduo mas também o conhecimento que dele se pode ter se originam dessa produção. (2002, p. 161). Na opinião de Machado, o fato de se considerar o poder capitalista como algo que descaracteriza e massifica o homem implica em considerar a existência anterior de algo como uma individualidade com características, desejos, comportamentos, hábitos, necessidades, que seria investida pelo poder e sufocada, dominada, impedida de se expressar. (Machado, 2001, p. XIX) (grifo meu)

Mas, para Foucault, como vimos, não pode haver uma individualidade anterior ou exterior às relações de poder, justamente porque é o poder disciplinar que produz as individualidades. Para Machado (2001, p. XX), “o indivíduo não é o outro do poder, realidade exterior, que é por ele anulado; é um de seus mais importantes efeitos”. (Machado, 2001, p. $\mathrm{XX})$

Assim, o louco não é anterior ao hospício, e sim o hospício que produz o louco como doente mental, individualizado a partir de relações de poder e saber tão bem analisadas na História da Loucura.

\section{Panoptismo}

Dentre os mais sofisticados dispositivos de poder, Foucault (2002) destaca o panoptismo. No século XVIII, foi criada por Bentham, principalmente para as prisões, uma estrutura arquitetônica bastante peculiar: há uma torre central, onde fica um único vigia; à sua volta, em celas individuais, ficam os presos. Extremamente bem planejada, a estrutura prevê jogos de luz que permitem que o vigia possa ter total visão dos presos, mas estes não têm qualquer visão do interior da torre, o que faz com que nem sequer possam saber se há ou não um vigia de plantão.

O efeito do panóptico é bastante crucial, já que a visibilidade permanente acarreta o funcionamento automático do poder. Já não era mais necessário, na verdade, haver alguém para controlar, já que o controle era auto-exercido pelo controlado, através de um olhar que se volta para dentro, para trás. A ação do panóptico é individual, porque atua sobre o corpo do indivíduo, mas é também coletiva, na medida em que atua sobre o corpo social. Como resultado, o poder disciplinar tornou-se internalizado. O panoptismo, para Foucault, faz

... com que a vigilância seja permanente em seus efeitos, mesmo se é descontínua em sua ação; que a perfeição do poder tenda a tornar inútil a atualidade de seu exercício; que esse aparelho arquitetural seja uma máquina de criar e sustentar uma relação de poder independente daquele que o exerce; enfim, que os 
detentos se encontrem presos numa situação de poder que eles mesmos são os portadores. (Foucault, 2002, p. 166)

Para Foucault, o panoptismo é uma invenção tecnológica que está para a ordem do poder assim como a invenção da máquina a vapor está para a ordem da produção (Foucault, 2001b, p. 160). Ou seja, ele atribui a essa nova estratégia grande significância, já que foi a partir da invenção de novas tecnologias que a burguesia pode assegurar a "irrigação" dos efeitos do poder sobre todo o corpo social, mesmo em suas mais ínfimas partículas. É por isso que Foucault considera Bentham como um dos mais exemplares inventores de tecnologia do poder (Foucault, 2001b, p. 218). Ainda que a idéia do panopticon seja anterior a Bentham, foi ele que, segundo Foucault, formulou e batizou o Panóptico. De acordo com a concepção foucaultiana, até o palavra é fundamental, pois "panopticon” designa um princípio de conjunto (Foucault, 2001b, p. 211).

É preciso perceber, entretanto, que mesmo o vigia é vigiado. Há o inspetor principal que, da torre central, controla não apenas os prisioneiros, mas também o pessoal responsável pelo enquadramento. É a hierarquização da vigilância em que ninguém confia em ninguém; todos são vigias e vigiados. Para Foucault, 2001b, p. 220, "no panopticon, cada um, de acordo com seu lugar, é vigiado por todos ou por alguns outros; trata-se de um aparelho de desconfiança total e circulante, pois não existe ponto absoluto. A perfeição da vigilância é uma soma de malevolências".

Inicialmente, o panoptismo foi utilizado a partir de condições locais e de urgências particulares (Foucault, 2001b, p. 222). Mas a partir de determinado momento, esses métodos foram generalizados; passou-se a experimentar a vigilância integral, nas escolas, por exemplo, passou-se a vigiar permanentemente o grupo escolar. Para isso era necessário hierarquizar a vigilância. É preciso, entretanto, compreender que, apesar de hierarquizados, há uma única linha de vigilância. Na descrição que faz do papel dos procuradores gerais do Império, Foucault (2002) os caracteriza como sendo todos o mesmo "olho do Imperador": "do primeiro procurador geral em Paris ao simples substituto de província, é um único olhar que vigia as desordens, prevê os perigos de criminalidade, sanciona todos os desvios". (Foucault, 2001b, p. 160) (grifo meu).

Porém, para que não restem dúvidas de que com essas idéias Foucault estaria defendendo a existência de um ponto central - o Estado - de onde o poder fosse irradiado, ele esclarece que os aparelhos de Estado não confiscaram o panoptismo, mas se apoiaram nesses pequenos panoptismos regionais e dispersos. Dessa forma, alerta Foucault (2001b, p. 160), 
não se deve limitar-se à análise dos aparelhos de Estado se o objetivo for compreender os mecanismos de poder em sua complexidade e detalhe.

Esse dispositivo de poder que no século XVIII dependia de uma estrutura arquitetônica que lhe desse suporte sofreu transformações que fizeram com que se tornasse ainda mais sofisticado. Podemos citar, como exemplo, uma tecnologia atual que dispensa a necessidade de uma estrutura arquitetônica especial: as câmeras de vídeo. Estações de metrô, bancos, lojas, elevadores, escolas, programas televisivos; há olhos incansáveis por toda parte. Sem dúvida, as câmeras constituem na sociedade atual o exemplo mais concreto de panoptismo, mas este fenômeno está em todos os lugares, mesmo naqueles desprovidos desse olhar biônico, uma vez que, na mesma medida em que aprendemos a nos autocontrolar aprendemos a controlar também o outro. Dessa forma, para Foucault (2002, p. 171), “o esquema panóptico, sem se desfazer nem perder nenhuma de sua propriedades, é destinado a se difundir no corpo social; tem por vocação tornar-se aí uma função generalizada".

Vê-se a partir dessas idéias a complexidade por que passa a concepção de poder para Foucault. O exercício de poder passa por canais absolutamente tênues, imperceptíveis, formando uma malha da qual ninguém escapa, que faz com que cada um de nós seja, intrinsecamente, titular de um certo poder e que, por isso, veicula poder (Foucault, 2001b, p. 160). Na escola, por exemplo, o panoptismo não passa apenas pelos olhos da professora, mas também do colega, que também vigia, que também controla, porque também exerce poder.

É a partir dessa concepção de poder que se deve analisar o panoptismo na escola. Por exemplo, uma análise apressada poderia concluir que a disposição das carteiras na sala de aula em círculos é mais libertadora do que a disposição em fileiras. O argumento utilizado para isso é o de que, dessa forma, o estudante teria mais possibilidade de se manifestar e de ser ouvido. O círculo seria assim visto como possibilidade de derrubada dos limites impostos pela disposição em fileiras, em que os estudantes ficam isolados, sem muita condição de interagir uns com os outros. A disposição em fileiras, ao contrário, é normalmente vista como repressiva, já que favorece ao controle por parte do professor, a partir da supervisão (supervisão) da sala de aula através das unidades coletivas que se formam com as fileiras. No entanto, uma análise mais acurada poderá revelar que não há práticas inerentemente libertadoras ou inerentemente opressivas, pois qualquer prática pode servir ao poder ou tornar-se uma fonte de resistência. É essa a conclusão que chega Gore (1994), baseando-se, entre outros autores, em Foucault. Ela afirma que, por um lado, a disposição em círculos, ao contrário de só libertar, pode servir também para exigir um maior autocontrole, já que o estudante fica muito mais visível aos olhos de todos, e não só da professora. Por outro, temos 
a disposição em fileiras, que, longe de só reprimir, pode favorecer a privacidade dos que quiserem permanecer anônimos.

Não é difícil perceber que em nossa sociedade de controle a velha arquitetura criada por Bentham foi substituída por aparatos muito mais sutis, que são imperceptíveis justamente porque são onipresentes. Estamos sendo controlados durante uma parte enorme do nosso dia-a-dia, quando entramos em um site na internet, quando pagamos nossas despesas com cartões de crédito, quando falamos ao celular, quando compramos alguma coisa pelo correio, quando nos diagnosticam alguma enfermidade num hospital, quando somos monitorados pelas câmeras instaladas na sala de aula onde estudamos ou onde lecionamos.

Apenas a título de provocação, deixo a mesma interrogação que encerra a terceira parte do livro Vigiar e Punir, intitulada Disciplina: devemos ainda nos admirar que a prisão se pareça com as fábricas, com as escolas, com os quartéis, com os hospitais, e todos se pareçam com as prisões? (Foucault, 2002, p.187)

\section{Referências Bibliográficas}

FOUCAULT, Michel. Tecnologías del yo. In: . Tecnologías del yo y otros textos afines. Barcelona: Edidiciones Paidós Ibérica, 1990.

FOUCAULT, Michel. O sujeito e o poder. In: DREYFUS, Hubert \& RABINOW, Paul. Michel Foucault: uma trajetória filosófico - para além do estruturalismo e da hermenêutica. Tradução de Vera Porto Carrero. Rio de Janeiro: Forense Universitária, 1995.

FOUCAULT, Michel. História da Sexualidade I: A vontade de saber. Tradução de Maria Thereza da Costa Albuquerque e J.A. Guilhon Albuquerque. Rio de Janeiro: Edições Graal, 2001a.

FOUCAULT, Michel. Microfísica do Poder. Organização e tradução de Roberto Machado. Rio de Janeiro: Edições Graal, 2001b.

FOUCAULT, Michel. Vigiar e punir: nascimento da prisão. Tradução de Taquel Ramalhete. Petrópolis, RJ: Vozes, 2002.

GORE, Jennifer. Foucault e educação: fascinantes desafios. In: SILVA, Tomaz Tadeu da (Org.). O sujeito da educação: estudos foucaultianos. Petrópolis, RJ: Vozes, 1994.

MACHADO, Roberto. Por uma genealogia do poder. In: FOUCAULT, Michel. Microfísica do poder. Rio de Janeiro: Edições Graal, 2001.

MAIA, Antônio. Sobre a analítica do poder de Foucault. In: Tempo Social. Ver. Sociol. USP, São Paulo, 7(1-2): 83-103, outubro de 1995. 